\title{
Nike K. Pokorn, Post-Socialist Translation Practices. Ideological struggle in children's literature, John Benjamins (Benjamins Translation Library, Volume 103), Amsterdam - Philadelphia 2012, 188 pp.
}

In Nike K. Pokorn's book interests vital for current research on translation and in the humanities at large, like ideologies, agency, ethics, coincide with methodological problems and blind spots likely to arise when one focuses on exposing translation in the service of hegemonic discourses. My concern with the latter aspect, together with the fact that the study has apparently only been reviewed once, encourages its somewhat delayed present discussion.

The title of the book is rather misleading. The study concerns mostly socialist, not postsocialist, translation practices, or, to be precise - one such practice in one sphere: obliterating religious references in translated children's fiction published in Slovene and other languages of the Socialist Federal Republic of Yugoslavia (SFRY). Comparative analysis is combined with statistical approach and the author further interprets the findings by reconstructing the sociological and ideological framework in which the translations were produced and received; she also proposes ethical conclusions.

The main text falls into ten unnumbered chapters. The first one, 'The voice of the East: Towards a Post-Socialist Translation Studies?', is a manifesto which I will discuss at the end.

In the second section the author explains the adopted framework. She validates her choice of investigating children's literature by the fact that this genre is particularly likely to be subjected to ideological manipulations. She presents the scope of her research - focusing on works for children retranslated (assumedly for political reasons) into Slovene in the 1945-1955 period — and outlines its stages. Methodologically, Pokorn states her affinity for Lefevere's concept of patronage and for Bourdieusian notions adopted in the sociology of translation, 'habitus' and 'translatorial field'. 
The next chapter briefly outlines the history of Slovenia, its language and culture, up to the last quarter of a century that saw the emancipation of the former SFRY republics. Against this background, data about the translation activity in the field of children's literature is given for each of the periods described. Appropriate graphs illustrate the frequency of translation from various source languages or the proportions between translated children's literature and texts for children originally written in Slovenian at different points of time. Some aspects of political situation in the post-war communist Yugoslavia are explicated, e.g. breaking off with the USSR, the nationalisation of the publishing industry or the institution of agitprop. Substantial attention is devoted to the Yugoslav communists' stance on religion and to their attitude towards the Catholic church, a step indicating the orientation of the analysis which is to follow. Finally, the corpus is presented. The author states more explicitly her tenet that, in view of the state cultural policy and of the economic difficulties experienced in the SFRY immediately after the Second World War, commissioning retranslations of specific children's books is likely to signify that their previous renditions were unacceptable or inconvenient for the new regime. The filtering of the general databases revealed 14 such retranslations, which, after some adjustments, formed a 13-element study corpus.

The next four chapters bring the account of the analysis conducted on this corpus, structured along the probable motives behind the retranslations: stylistic reasons, disapproval of the previous translators, presence of ideologically inconvenient textual elements.

The first analytical section, 'Stylistic reasons and problematic translators', deals with two of the distinguished categories at once, wherein the potential criteria partly overlap. Kipling's The Second Jungle Book and Twain's The Adventures of Tom Sawyer appear to have indeed required retranslations for linguistic quality. Three books - Tom Sawyer, Collodi's Pinocchio and Kästner's Pünktchen und Anton - are classified as having had translators unacceptable for the new regime for biographical-ideological reasons: a Catholic poet tainted with collaboration, a priest, a right-wing Catholic émigré editor and poet. This is why, Pokorn diagnoses, preparing new renditions was entrusted by the regime to the 'right' translators, who were part of the socialist cultural or even political establishment.

The other three analytical chapters explore books which, in Pokorn's view, were retranslated in the critical decade because of containing passages incompatible with the official ideology. In each case the potentially subversive fragments are examined in the original, in the pre-1945 Slovene rendition(s) and in the socialist retranslation. This is followed by a succinct account of later translations and reprints; moreover, any translations available in SerboCroat (or Serbian, Croatian, Bosnian) and Macedonian are also consulted to check if they confirm the tendencies observed in the Slovenian editions. Thus, the total number of translations into the languages of the SFRY taken into account for an individual source text often exceeds twenty. As in the previous chapter, the translators are very much visible, their lives and achievements featuring importantly in the analysis.

As could be expected, the translations executed in the 1945-1955 period (and many of the later socialist ones as well) indeed turn out to have been tampered. The three chapters offer ample illustrations of the well-known fact of the erasure of religious content in socialist publications, therefore the analysis is at its most interesting where less predictable phenomena are observed. For instance in Johanna Spyri's Heidi the references to faith are systematic and form a prominent element of the plot. To purge such an overtly religious novel, local translational interventions would not suffice, it demands a consistent rewriting strategy. 
Pokorn shows (pp. 94-108) how such a strategy, probably originating from a Serbian translation, was successful enough to have been copied and perpetuated across versions published in different republics, turning this unlikely candidate into a socialist bestseller. The analysis of May's Winnetou (pp. 82-94), in turn, overcomes the restricted perspective of research. Here, diverse elements prove ideologically sensitive: the narrator's German identity, the revolutionary past of Kleki-Petra and his regret for his earlier deeds, as well as references to Christianity, including Winnetou's declared conversion before his death. Shifts aimed at suppressing these elements are reported, occurring in translations in various combinations.

The subsequent three chapters provide an extension of the research and help contextualise the results.

'Post-socialist practices' only come into view in the eighth chapter, 'Translation in Slovene primary school textbooks and readers'. After explaining the functioning of Slovene educational system, Pokorn examines current government-approved textbooks for the presence of religiously manipulated renditions and finds a high percentage of such reprints in them. The fact that translations of children's books from the socialist period are still being reprinted after the political transformations in the countries of the former Yugoslavia is interpreted as a symptom of the education-policy makers' (and the society's) unawareness of textual manipulations. It should be noted that the picture might be more complicated, as legal contexts are largely left out of the analysis, and economic factors are acknowledged fleetingly in the last but one paragraph of the book. It is also not made clear why textbook reprints should be essentially problematic if the passages in the textbooks are not necessarily the ones that have been manipulated.

The next chapter, titled 'Translation has always been a political matter', begins with a summary of the findings. To contextualise them, the author provides an insight into the functioning of censorship - officially non-existent - in socialist Slovenia, based on researching minutes of the meetings of the Communist Party's Politburo and of numerous committees overseeing cultural activities. She describes how the ideological correctness of prints was tacitly secured at the level of publishing houses, making actual state censorship unnecessary. The archival research is complemented by interviews with one current and three retired editors of children's fiction. The interviews show how strongly, in absence of external institutional pressure, the preventive censorship was internalised, even - in the case of Kristina Brenk, the translator of Felix Salten's Bambi - to the point of a complete denial of having introduced any textual changes.

While this chapter ends on a surprisingly philosophical note - the betrayal revealing the existence of a true meaning - in the closing section, 'The illusion of interference', Pokorn recapitulates some of her points and raises, if in a rather alarmist way, the ethical questions connected with the socialist translation practices and their post-socialist extensions.

The book is not particularly well organised, which at times makes it difficult to follow or impairs the author's reliability. For instance, the choice of the narrow perspective is clearly explained only after the results of the analysis have been summarised (pp. 139-140). The answers to some questions or doubts arising when reading are scattered in the text or given unduly late; certain governing ideas are repeated in several places rather than pointedly expressed at an initial stage. The index, which could help moving among the dense factual information, is essentially a subject one, supplemented with selected (on what principle?) personal 
names and one book title. Regrettably for a study which focuses so much on translators, the index does not cover them.

The author claims to have analysed 217 translations 'in detail' (p. 139). However impressive the varied research apparent in the study, the sheer amount of data swings the balance in favour of quantitative analysis at the expense of full-text comparative analysis and hermeneia. The author diligently records all the erasures and conducts statistical analysis on them, but often refrains from probing how the pruning has influenced the texts qualitatively. Certainly, not all of the shifts affect the interpretative potential of the text, so excessive gravity need not be attributed to them. On the contrary, if Bambi mechanically repeats some words of his mentor instead of making an inference about the existence of God, the translational shift subverts the idea of the coming-of-age novel that should leave the character grown up and able to think independently - a problem which goes unnoticed in the analysis (pp. 80-81).

Moreover, other potential manipulations of the discussed texts are not considered, hence it is difficult to take for granted the assurance that certain translations were ideologically unchanged' (pp. 111, 122) simply on the grounds that some characters remain pious. The claim that Michel Strogoff includes very few instances that might prove problematic to the Communist ideology' (p. 126) is even more controversial, since Verne offers a very positive image of tsar Alexander II - in a people's democracy this aspect is likely to prove more problematic than scattered religious references.

To sum up, Pokorn's study has a broad scope (the list of primary sources contains over 320 items) but a narrow perspective. Naturally, as with focus and depth in photography, these parameters can be variously adjusted; yet in the opening paragraph the author promises to 'attempt to identify these disturbing elements and outline the typical and defining features of translatorial behaviour' (p. 1). There is, however, only one kind of 'disturbing elements' identified, i.e. references to the Christian religion, and only one type of translatorial behaviour, that of internalised self-censorship. Meanwhile, the politics of translation in any totalitarianism is undoubtedly a multifaceted phenomenon, often involving defiance as well, and censorship itself can be oriented towards eliminating extremely varied 'unwanted' material.

This brings us back to the initial manifesto. Placed at the beginning is what emerges from the study: an appeal for further research, as well as for the formation of Post-Socialist Translation Studies. Analyses focusing on former communist states do tend to appear, e.g. in most of the recent collections devoted to the interface of translation and power, yet an urge to intensify the research is not malapropos.

In her appeal, Pokorn stresses the ethical dimension of research and the need to raise the general public's awareness of ideologies imbedded in culture and of their lasting influence. Among the tasks to be undertaken she enumerates revealing the abuses, but also the accomplishments of socialist translation and interpreting, as well as promoting internationally major TS research from that period (p. 5). I would like to emphasise the last two aspects: despite the rather bleak picture of the translational field and translators' habitus emerging from Nike Pokorn's analyses, the Post-Socialist TS, if we construct it, should not be limited to unmasking and condemning; it should as well affirm artistic and theoretical achievements from the difficult past.

MARTA KAŹMIERCZAK 